\title{
Supraphysiological Testosterone Levels Shorten the QT Interval but do Not Alter Total Anatomic Myocardial Infarct Size in Rabbits with Acute Myocardial Infarction
}

\author{
Michael J. Herring ${ }^{* 1}$, Sharon L. Hale ${ }^{1}$, Jianru Shi ${ }^{1}$, Peyman Mesbah Oskui ${ }^{1,2}$, Gregory Kay and Robert A. Kloner ${ }^{1,3}$ \\ ${ }^{1}$ Heart Institute, Good Samaritan Hospital, Los Angeles, California, USA \\ ${ }^{2}$ Harbor-UCLA Medical Center, Department of Cardiology, Torrance, California, USA \\ ${ }^{3}$ Keck School of Medicine at the University of Southern California, Department of Cardiology, Los Angeles, California, USA
}

\begin{abstract}
Introduction: A growing number of men are using exogenous testosterone $(T)$ to treat hypogonadism and to enhance athletic performance. However, some studies suggested that $\mathrm{T}$ increased adverse cardiovascular events. Although T has been shown to increase apoptosis, its effect on total acute myocardial infarction (MI) size is largely unknown. We hypothesized that T might increase MI size.
\end{abstract}

Materials and Methods: Male rabbits received an intramuscular injection of either $T(50 \mathrm{mg} / \mathrm{kg})$ or saline one week before receiving 30 minutes of coronary artery occlusion/ 3 hours of coronary artery reperfusion.

Results: The T levels in the treated group were higher than those of the control group: $15 \pm 1 \mathrm{ng} / \mathrm{mL} T(n=18)$ versus $1 \pm 1 \mathrm{ng} / \mathrm{mL}$ control ( $\mathrm{n}=20, P<0.01)$. Anatomic Ml size (tetrazolium staining) expressed as a percentage of the ischemic risk zone (blue dye technique) was similar in both groups: $37 \pm 3 \%$ in controls and $37 \pm 5 \%$ in the T group $(P=0.96)$. T significantly shortened the QTc interval by $9 \%(P=0.03)$.

Conclusions: Supra physiological levels of T did not increase infarct size. T shortened the QTc interval, which may create an anti-arrhythmic substrate.

Keywords: Testosterone; QT interval; Ischemia reperfusion; Myocardial infarction; Cardio protection

\section{Introduction}

Testosterone (T) was first synthesized in 1935 to treat young men with hypogonadism [1]. Over the past decade, T has become extremely popular in both clinical and athletic practices for both legal and illegal purposes. Due to the increasing number of men using $\mathrm{T}$ for medical conditions such as hypogonadism, low libido and weakness, [2] as well as the large number of professional and amateur athletes utilizing testosterone as a performance enhancing drug [3] in order to increase lean body mass, [4-6] the cardiovascular risks from using, and often abusing, exogenous testosterone should be examined. The effect of estrogen on the size of myocardial infarctions has been well documented with little controversy, [7-10] but the role of testosterone has yet to be defined clearly [11]. Some studies suggest positive cardiovascular effects of testosterone with regards to QT segment duration [12-14] and that higher testosterone levels are associated with a lower risk of cardiac mortality [15] and better functional capacity [16]. However, other evidence suggests that testosterone exerts a negative impact on the cardiovascular system with regards to apoptosis [17-20] and adverse cardiac events [21].

Little is known about the effect of testosterone on myocardial infarct (MI) size in the experimental ischemia/reperfusion model. We hypothesized that supra physiological levels of testosterone would shorten the QT interval, worsen cardiac function and increase the size of the zone of no-reflow and the necrotic region in our experimental model.

\section{Methods}

The animals used in these studies were maintained in accordance with the policies and guidelines of the Position of the American Heart Association on research animal use (American Heart Association,
1985) and the Guide for Care and Use of Laboratory Animals (2010). The Good Samaritan Hospital Institutional Animal Care and Use Committee approved this protocol.

\section{Pilots}

To determine proper dosing of testosterone, 7 pilot rabbits were given intramuscular injections of either $5 \mathrm{mg} / \mathrm{kg}$ testosterone cypionate (T, Paddock Labs, Minneapolis, MN, $\mathrm{n}=1$ ), 15mg/kg T ( $\mathrm{n}=2), 45 \mathrm{mg} /$ $\mathrm{kg}(\mathrm{n}=2)$ or $50 \mathrm{mg} / \mathrm{kg}(\mathrm{n}=2)$ on day zero after baseline blood samples were taken. Blood samples were then taken at days 1, 3, 4 and 7 to determine total $\mathrm{T}$ concentration. The goal of these pilots was to determine the appropriate concentration and time after the injection that total $\mathrm{T}$ blood levels be at least 8 times higher than base line (in order to simulate doses that increased muscle size and strength) [22]. After testing the various concentrations, the dose of $50 \mathrm{mg} / \mathrm{kg}$ one week before surgery was chosen as it consistently gave us levels greater than 8 times baseline [22].

\section{Surgical preparation}

Male New Zealand White rabbits (2.4-3.7kg) were randomized

*Corresponding author: Michael Herring, B.S, Heart Institute Good Samaritan Hospital1225 Wilshire BIvd. Los Angeles, CA 90017-2395, Tel: (213) 977-4040; Fax: (213) 977-4107; E-mail: mherring26@gmail.com

Received January 15, 2014; Accepted January 24, 2014; Published January 31 2014

Citation: Herring MJ, Hale SL, Shi J, Oskui PM, Kay G, Kloner RA (2014) Supraphysiological Testosterone Levels Shorten the QT Interval but do Not Alter Total Anatomic Myocardial Infarct Size in Rabbits with Acute Myocardial Infarction. Cardiol Pharmacol 3: 115. doi:10.4172/2329-6607.1000115

Copyright: (c) 2014 Herring MJ, et al. This is an open-access article distributed under the terms of the Creative Commons Attribution License, which permits unrestricted use, distribution, and reproduction in any medium, provided the original author and source are credited. 
Citation: Herring MJ, Hale SL, Shi J, Oskui PM, Kay G, Kloner RA (2014) Supraphysiological Testosterone Levels Shorten the QT Interval but do Not Alter Total Anatomic Myocardial Infarct Size in Rabbits with Acute Myocardial Infarction. Cardiol Pharmacol 3: 115. doi:10.4172/23296607.1000115

\begin{tabular}{|c|c|c|c|c|}
\hline $\begin{array}{l}\text { Mea- } \\
\text { sure- } \\
\text { ment }\end{array}$ & Time & $\begin{array}{l}\text { Testosterone (Average } \\
\pm \text { SEM) }\end{array}$ & $\begin{array}{l}\text { Control (Average } \\
\pm \text { SEM) }\end{array}$ & $P$ Value \\
\hline \multirow[t]{6}{*}{$\mathrm{pH}$} & Baseline & $7.5601 \pm 0.018$ & $7.5249 \pm 0.02$ & 0.22 \\
\hline & $25^{\prime}$ Occl & $7.5441 \pm 0.015$ & $7.5078 \pm 0.017$ & \\
\hline & 30' Rep & $7.5223 \pm 0.016$ & $7.4847 \pm 0.012$ & \\
\hline & 60' Rep & $7.4962 \pm 0.017$ & $7.4793 \pm 0.012$ & \\
\hline & 90' Rep & $7.484 \pm 0.018$ & $7.4667 \pm 0.011$ & \\
\hline & 120' Rep & $7.4396 \pm 0.017$ & $7.4501 \pm 0.01$ & \\
\hline \multirow[t]{6}{*}{ pO2 } & Baseline & $130.8938 \pm 13.172$ & $144.995 \pm 10.846$ & 0.43 \\
\hline & $25^{\prime}$ Occl & $103.0625 \pm 5.54$ & $115.1947 \pm 7.724$ & \\
\hline & 30' Rep & $109.34375 \pm 5.297$ & $108.42 \pm 7.931$ & \\
\hline & 60' Rep & $111.675 \pm 6.317$ & $111.15 \pm 9.053$ & \\
\hline & 90' Rep & $120.62 \pm 5.238$ & $127.02 \pm 6.589$ & \\
\hline & 120' Rep & $114.94375 \pm 6.224$ & $129.4111 \pm 6.479$ & \\
\hline \multirow[t]{6}{*}{$\mathrm{pCO} 2$} & Baseline & $38.8063 \pm 2.886$ & $41.12 \pm 2.965$ & 0.02 \\
\hline & $25^{\prime}$ Occl & $32.3125 \pm 2.56$ & $39.1211 \pm 2.75$ & \\
\hline & 30' Rep & $32.2313 \pm 2.705$ & $40.56 \pm 2.603$ & \\
\hline & 60' Rep & $32.4938 \pm 2.245$ & $40.945 \pm 3.797$ & \\
\hline & 90’ Rep & $32.44 \pm 2.061$ & $37.36 \pm 1.482$ & \\
\hline & 120' Rep & $32.62 \pm 1.961$ & $36.2471 \pm 1.55$ & \\
\hline \multirow[t]{6}{*}{$\mathrm{SO} 2$} & Baseline & $96.7125 \pm 1.658$ & $97.99 \pm 0.662$ & 0.76 \\
\hline & 25' Occl & $96.2133 \pm 1.515$ & $95.4526 \pm 2.29$ & \\
\hline & 30' Rep & $97.84 \pm 0.319$ & $95.885 \pm 1.521$ & \\
\hline & 60’ Rep & $97.5733 \pm 0.423$ & $96.045 \pm 1.602$ & \\
\hline & 90' Rep & $98.1571 \pm 0.222$ & $97.145 \pm 1.251$ & \\
\hline & 120' Rep & $95.65 \pm 1.771$ & $97.3833 \pm 0.654$ & \\
\hline
\end{tabular}

Table 1: Blood gas measurementspCO2 levels were higher in the control versus the T group, yet all levels were within the normal range.

using a random number generator to receive either an intramuscular (IM) injection of $\mathrm{T}(50 \mathrm{mg} / \mathrm{kg}, \mathrm{n}=20)$ or saline $(\mathrm{n}=22) 1$ week before surgery. Only one dose of testosterone was given in an attempt to determine the effectiveness of testosterone as an acute therapy of acute MI. On the day of surgery, rabbits were anesthetized by an IM injection of ketamine $(50 \mathrm{mg} / \mathrm{kg}$, JHP Pharmaceuticals, Rochester, MI) and xylazine $(10 \mathrm{mg} / \mathrm{kg}$, Lloyd Labs, Shenandoah, IA).A second dose was given 5 to 10 minutes before surgical preparation. Intravenous (IV) sodium pentobarbital (Lund beck Inc., Deerfield, IL) was given during the procedure as necessary to ensure deep anesthesia. Tracheotomies were performed and rabbits were ventilated mechanically with oxygenenriched air. Catheters filled with heparinized saline were inserted into the left jugular vein for anesthesia administration and into the left carotid artery for hemodynamic measurements and blood sample extraction in order to measure blood gas levels.ECG electrodes were inserted into the muscle of each hind leg and the right foreleg of the rabbits. The heart was exposed by opening the chest at the fourth left inter-costal space. A pericardial cradle was created if access to the myocardium was obstructed by the lung. Coronary artery occlusion (CAO) was accomplished by threading a 4-O silk suture around the circumflex artery near the left atrial appendage and creating a snare by threading the ends of the suture through a piece of plastic tubing. Tightening this snare induced a CAO. Rectal temperature was continuously monitored with a probe, and body temperature was maintained with a heating pad.

\section{Experimental protocol}

Baseline hemodynamic, blood gas, and ECG readings were taken 5 minutes prior to CAO. Rabbits were then subjected to 30 minutes of $\mathrm{CAO}$ by tightening the snare and securing it with a clamp.
Hemodynamic, blood gas, and ECG readings were obtained after 25 minutes of CAO. After 30 minutes of CAO, the snare was loosened and the rabbits underwent 3 hours of coronary artery reperfusion (CAR).Hemodynamic and blood gas measurements were taken at $30,60,90$, and 120 minutes of reperfusion. ECG tracings to measure QT segment duration and echocardiography images to measure regional ejection fraction and fractional shortening were obtained at 175 minutes of reperfusion. At the end of the study, a catheter filled with heparinized saline was inserted into the left atrial appendage and $1 \mathrm{mg} / \mathrm{kg}$ of $4 \%$ Thioflavin S solution was injected to define the area of no-reflow. Thioflavin S binds to endothelial cells, making it a marker for perfusion, causing the area of perfusion to fluoresce greenyellow under ultraviolet light, thus the area of no-reflow appears nonfluorescent (dark).After Thioflavin S circulated, the coronary artery was re-occluded and 4 milliliters of a $50 \%$ solution of Unisperse blue dye (Ciba-Geigy, Hawthorne, NY) were injected into the left atrial appendage to delineate the area of ischemic risk. The ischemic risk zone remained pink, while the area not at ischemic risk stained blue. Under deep anesthesia, rabbits were sacrificed by injecting $12 \mathrm{mEq}$ of potassium chloride. The heart was then removed and analyzed.

\section{Blood gas and hemodynamic measurements}

Blood gas and hemodynamic measurements were taken at baseline, 25 minutes of occlusion and 30, 60, 90 and 120 minutes of reperfusion. Blood gas measures examined were $\mathrm{pH}, \mathrm{O} 2$ partial pressure, $\mathrm{CO} 2$ partial pressure and $\mathrm{O} 2$ saturation (NOVA Biomedical, Waltham, MA).

Mean arterial blood pressure was measured via a catheter filled with heparinized saline inserted into the left carotid artery. Heart rate was measured on ECG tracings with the pulsatile blood pressure recording serving as backup. For each measurement, three consecutive heartbeats were measured and the data were averaged. Data were measured and analyzed using the Advanced Digital Instruments (ADI, Grand Junction, CO) system.

\section{Analysis of no-reflow area, risk zone and necrotic region}

Hearts were cut transversely into 6 to 8 sections. Hearts were photographed under ultraviolet light to show the area of no-reflow, and then under standard lighting to show the risk zone. Hearts were next incubated in a $1 \%$ solution of triphenyl tetrazolium chloride for 15 minutes to show the necrotic region. Hearts were subsequently rephotographed. Measurements were obtained by planimetric tracing with Image J software to determine areas of interest [23]. Areas were multiplied by heart slice weight to calculate the weight of each area. Weights were summed to obtain the weights of the no-reflow, risk, and necrotic zones.

\section{Analysis of QT Duration}

QT durations were corrected using Bazett's formula, or QTc = $\mathrm{QT} / \sqrt{\mathrm{RR}}$, where $\mathrm{RR}=60 / \mathrm{HR}$ [24]. Bazett's formula is one of the most commonly and widely used QT correctional formulae in the clinical literature. [25-27]. QTc was measured at baseline ( $\mathrm{n}=14 \mathrm{~T}, \mathrm{n}=15$ control), 25 minutes of occlusion $(\mathrm{n}=14 \mathrm{~T}, \mathrm{n}=18$ control) and 175 minutes of reperfusion ( $\mathrm{n}=15 \mathrm{~T}, \mathrm{n}=15$ control). Three consecutive heartbeats were analyzed for QT duration at each time point and averaged.

\section{Statistics}

Data were collected and analyzed using Excel spread sheets. Student's T-tests were performed with Stat Plus Software (Analyst Soft, 
Citation: Herring MJ, Hale SL, Shi J, Oskui PM, Kay G, Kloner RA (2014) Supraphysiological Testosterone Levels Shorten the QT Interval but do Not Alter Total Anatomic Myocardial Infarct Size in Rabbits with Acute Myocardial Infarction. Cardiol Pharmacol 3: 115. doi:10.4172/23296607.1000115

Page 3 of 5

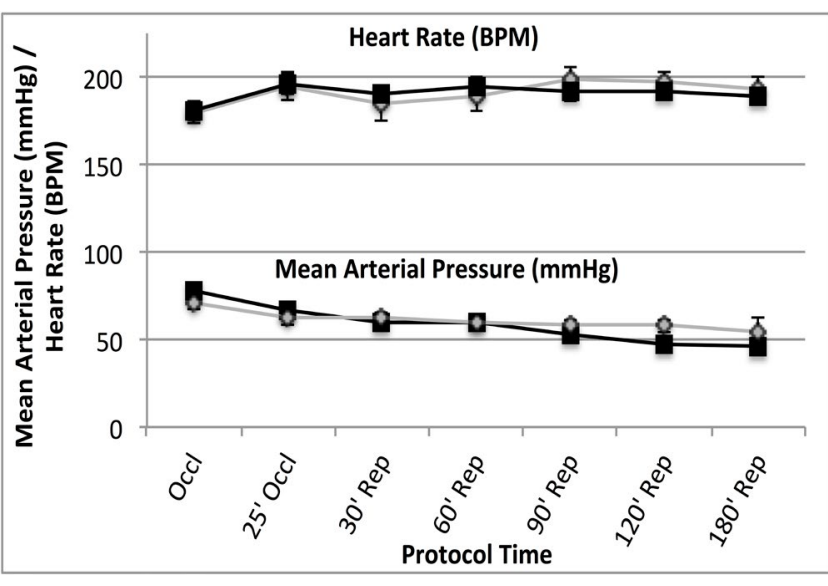

Figure 1: Hemodynamic measurements of Mean Arterial Pressure $(\mathrm{mmHg})$ and Heart Rate (BPM).P = NS for all measures.

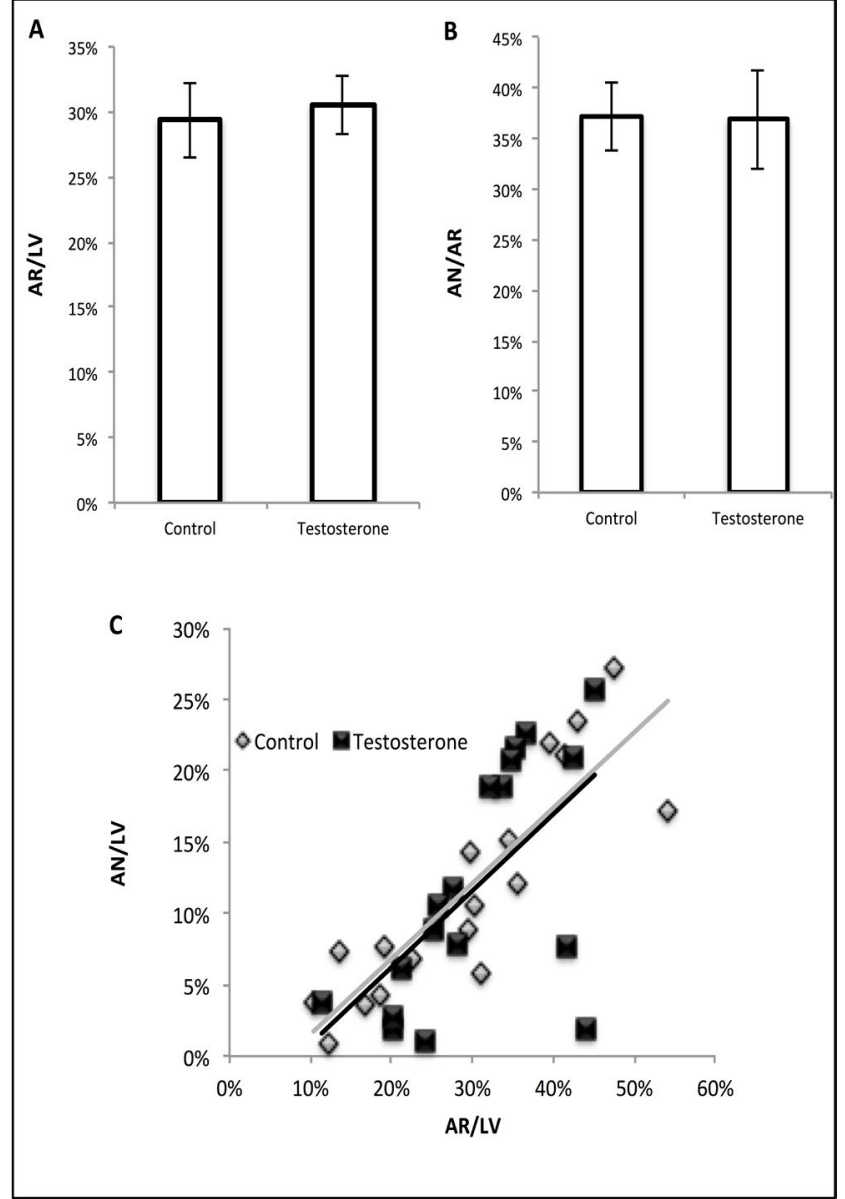

Figure 2: Area at risk and area of necrosis analysisA, the size of the area at risk for each group. $B$, the size of the area of necrosis as a percentage of the area at risk for each group.C, the relationship between the size of the risk area and the size of the area of necrosis for each group ( $P=N S)$. AR denotes area at risk; AN denotes area of necrosis.
Alexandria, VA).Repeated measures analysis of variance and analyses of covariance were performed with SAS (Version 9, Cary, NC). Data are expressed as mean \pm SEM.

\section{Results}

\section{Animals}

A total of 42 animals were included in this protocol. Two animals died before the end of the protocol due to arrhythmias, two animals were excluded due to a small ischemic risk zone, and one animal died as a result of malfunctioning equipment. The remaining 37 animals were studied: Testosterone, $\mathrm{n}=18$; Control, $\mathrm{n}=19$. There was no differences in $\mathrm{pH}, \mathrm{pO}_{2}$ and $\mathrm{O}_{2}$ saturation between groups. There was a small but significantly higher $\mathrm{pCO}_{2}$ in the control group as ventilation early in the protocol is difficult to control $(\mathrm{P}<0.05)$; however the absolute values for $\mathrm{pCO}_{2}$ were well within the normal range for both groups (Table 1) [28]. Hemodynamic measurements (Figure 1) were similar in both groups ( $P=\mathrm{NS}$ for all measures). Testosterone levels in the treated group were higher than in the control group: $14.6 \pm 1.3 \mathrm{ng} / \mathrm{mL} \mathrm{T}$ versus $1.4 \pm 0.7 \mathrm{ng} / \mathrm{mL}$ control $(\mathrm{P}<0.01)$.

Baseline body temperature, an independent predictor of infarct size, was $38.15 \pm 0.2^{\circ} \mathrm{C}$ in the T group and $38.18 \pm 0.2^{\circ} \mathrm{C}$ in the control group, respectively. Body weight was $2.9 \pm 0.07 \mathrm{~kg}$ and $2.9 \pm 0.06 \mathrm{~kg}$, respectively. Left ventricle (LV) weight was $4.2 \pm 0.2$ gram and $4.2 \pm 0.1$ $\mathrm{g}$, respectively. None of these differences were statistically significant throughout the study ( $\mathrm{P}=\mathrm{NS}$ for all measures).
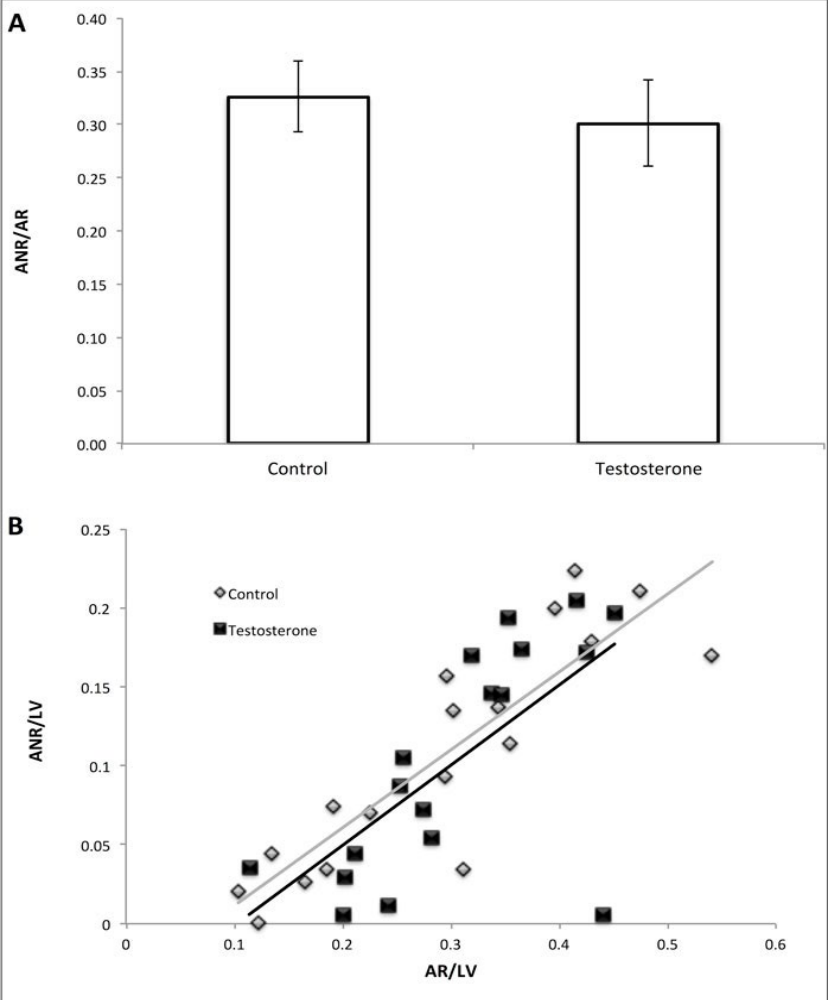

Figure 3: Area of no-reflow analysisA, the size of the area of No-reflow as a percentage of the area at risk for each groupB, the relationship between the size of the area at risk and the size of the area of no reflow for each group $(P=N S)$. $\mathrm{AR}$ denotes area at risk; ANR denotes area of no-reflow. 
Citation: Herring MJ, Hale SL, Shi J, Oskui PM, Kay G, Kloner RA (2014) Supraphysiological Testosterone Levels Shorten the QT Interval but do Not Alter Total Anatomic Myocardial Infarct Size in Rabbits with Acute Myocardial Infarction. Cardiol Pharmacol 3: 115. doi:10.4172/23296607.1000115

\section{Risk zone, infarct size and area of no reflow}

Areas at risk (AR) as a percentage of the LV (Figure $2 \mathrm{~A}$ ) were similar in both groups: $30.5 \pm 2 \%$ testosterone and $29.4 \pm 3 \%$ control $(\mathrm{P}=0.75)$. The infarct sizes, or areas of necrosis $(\mathrm{AN})$ as a percentage of the AR (Figure $2 \mathrm{~B}$ ) were also similar in both groups: $36.9 \pm 5 \%$ testosterone and $37.1 \pm 3 \%$ control $(\mathrm{P}=0.96)$. When $\mathrm{AN}$ was expressed as a function of AR (Figure $2 \mathrm{C}$ ), analysis of covariance (ANCOVA) revealed no significant differences between groups $(\mathrm{P}=0.83)$.

Areas of no-reflow as a percentage of the AR (ANRs, Figure 3A) were similar in both groups: $30.1 \pm 4 \%$ testosterone and $32.6 \pm 3 \%$ control $(\mathrm{P}=0.64)$. When ANR size was expressed as a function of AR (Figure 3B), ANCOVA revealed no significant differences between groups $(P=0.59)$.

\section{Cardiac function}

LVEF and LVFS were similar in both groups: $54.8 \pm 5 \% \mathrm{~T}$ versus $53.5 \pm 3 \%$ control $(\mathrm{P}=0.82)$ and $40.3 \pm 3 \% \mathrm{~T}$ versus $37.9 \pm 3 \%$ control $(\mathrm{P}=0.57)$ respectively (Figure 4$)$.

\section{QTc}

Baseline QTc duration times were $293 \pm 9 \mathrm{~ms}$ and $322 \pm 9 \mathrm{~ms}$ for T and control, respectively $(\mathrm{P}=0.03)$. At 25 minutes of occlusion and 180

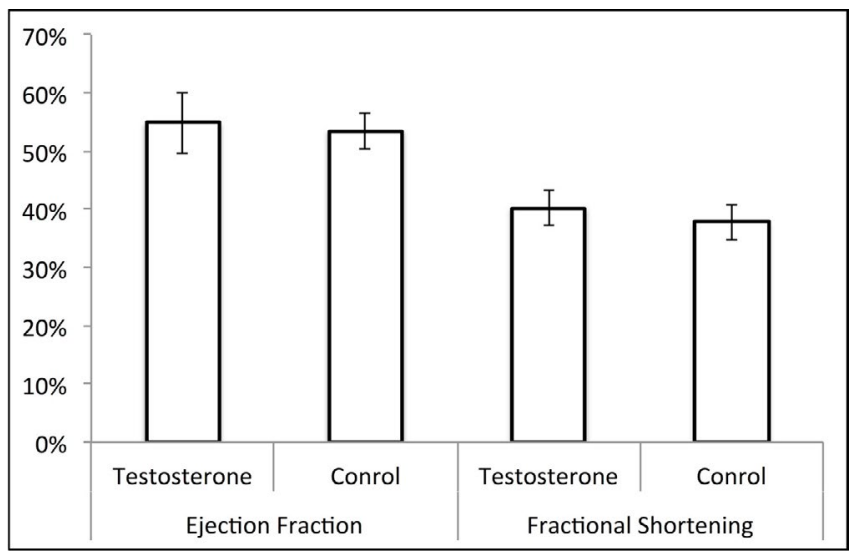

Figure 4: Post-MI cardiac function measurements for each group.Regional ejection fraction and fractional shortening comparisons $(P=N S)$.

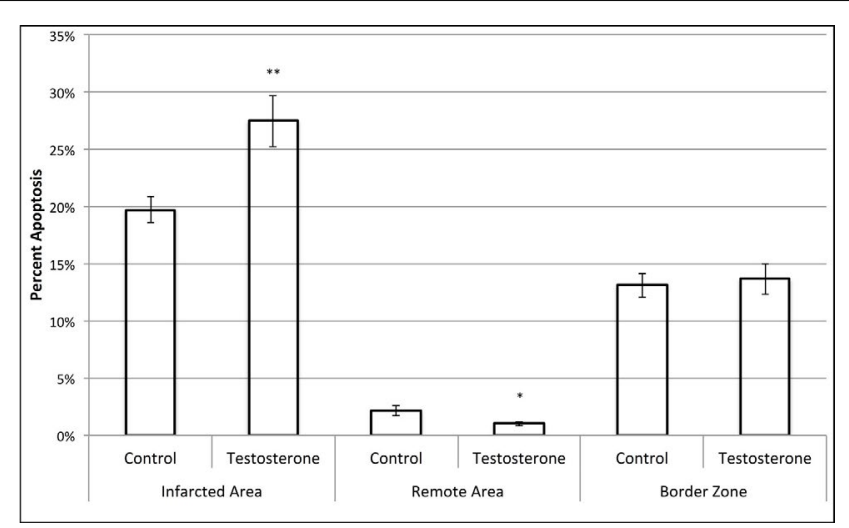

Figure 5: Corrected QT segment duration at baseline, 25 minutes of occlusion, and 180 minutes of reperfusion $\left({ }^{*}, \mathrm{P}<0.05\right.$ compared to control). minutes of reperfusion, there were no differences in QTc (25 minutes of occlusion: $311.8 \pm 12.3 \mathrm{~ms} \mathrm{~T}$ versus $334.3 \pm 10.3 \mathrm{~ms}$ control, $\mathrm{P}=$ 0.17 ; 180 minutes of reperfusion: $335.2 \pm 5.5 \mathrm{~ms}$ T versus $345 \pm 9.8 \mathrm{~ms}$ control, $\mathrm{P}=0.39$, (Figure 5).

\section{Discussion}

Administration of exogenous $\mathrm{T}$ has gained popularity for the treatment of hypogonadism, decreased libido and fatigue and increasing muscle size and strength. Despite warnings about the cardiovascular safety of exogenous T, [21] the number of T prescriptions has nearly tripled over the past decade [2]. Previous studies have suggested that reduced testosterone level causes an increase in experimental MI size, as orchiectomized animals showed larger MI size than both control animals and orchiectomized animals with T supplementation [29,30]. A recent study published in JAMA [31] reported a higher incidence of adverse cardiovascular events in male veterans receiving testosterone therapy for hypogonadism versus control male veterans receiving no testosterone. Although the difference was found to be statistically significant, this was a non-random, retrospective study in which only male veterans with coronary artery disease were included in this study [31]. A prospective, randomized, placebo-controlled study in which cardiovascular outcomes are the primary endpoint will be required to quell the controversy regarding testosterone therapy in the clinical setting. To our knowledge, our study is the first to examine the effect of supra physiological levels of testosterone on infarct size in an acute model. The present study suggests that supra physiological levels of testosterone did not adversely affect the outcome of myocardial infarction when compared to physiological levels of testosterone in an experimental model. Our data suggested that administration of exogenous testosterone had no effect on acute MI size, the extent of no-reflow or post-MI cardiac function. In fact, exogenous testosterone shortened the QTc interval. Testosterone did not cause abnormal blood gas levels or abnormal hemodynamic readings.

Our findings concerning QTc reflect those of Bai, Brouilette and coworkers, [13,14] suggesting that testosterone shortens QTC segment duration. This may have an important clinical implication as a shortened QTc segment has been associated with a lower incidence of arrhythmias [24]. Also, while prolongation of the QTc carries the majority of the pro-arrhythmic risks and it is associated with at least 10 genetic mutations [32], short QT syndrome also comes with risks. Short QT intervals have been shown to cause arrhythmias, but the mechanism of this disease is limited in scope and tends to affect infants, children and young adults [33]; individuals unlikely to be receiving testosterone therapy.

Despite the evidence suggesting that $\mathrm{T}$ increases apoptotic cell death, [17-20] the present study suggests that the use of exogenous testosterone at supra physiological levels is safe regarding MI size, area of no-reflow and post-MI cardiac function. This study also suggests that supra physiological levels of testosterone may in fact be beneficial in the scope of creating an anti-arrhythmia setting by shortening the QTc interval. However, more research is needed to determine the effect of testosterone on arrhythmias.

\section{Limitations}

While we focused on the effect of testosterone on acute myocardial infarctions, we did not examine other effects of testosterone. Such effects include lean body mass [22] (although there was no difference in weight between groups) and inflammatory biomarkers [34].The purpose of our pilot studies was to determine a dose of testosterone that attained a supra physiological level as described in the literature 
Citation: Herring MJ, Hale SL, Shi J, Oskui PM, Kay G, Kloner RA (2014) Supraphysiological Testosterone Levels Shorten the QT Interval but do Not Alter Total Anatomic Myocardial Infarct Size in Rabbits with Acute Myocardial Infarction. Cardiol Pharmacol 3: 115. doi:10.4172/23296607.1000115

Page 5 of 5

[22]. Once this dose was obtained, we did not think it was necessary to carry out a concentration - response study or to study other time points. The main purpose was to induce an experimental myocardial infarction at the time testosterone levels were elevated, and we achieved that goal.

\section{Acknowledgements}

This study was supported by a generous grant from the Los Angeles Thoracic and Cardiovascular Foundation.

\section{Reference}

1. White CM, Ferraro-Borgida MJ, Moyna NM, McGill CC, Ahlberg AW, et al. (1998) The pharmacokinetics of intravenous testosterone in elderly men with coronary artery disease. J Clin Pharmacol 38: 792-797.

2. Baillargeon J, Urban RJ, Ottenbacher KJ, Pierson KS, Goodwin JS (2013) Trends in androgen prescribing in the United States, 2001 to 2011. JAMA Intern Med 173: 1465-1466

3. Basaria S (2010) Androgen abuse in athletes: detection and consequences. J Clin Endocrinol Metab 95: 1533-1543.

4. Filippi S, Vignozzi L, Morelli A, Chavalmane AK, Sarchielli E, et al. (2009) Testosterone partially ameliorates metabolic profile and erectile responsiveness to PDE5 inhibitors in an animal model of male metabolic syndrome. J Sex Med 6: 3274-3288.

5. Gupta V, Bhasin S, Guo W, Singh R, Miki R, et al. (2008) Effects of dihydrotestosterone on differentiation and proliferation of human mesenchymal stem cells and preadipocytes. Mol Cell Endocrinol 296: 32-40.

6. Page ST, Amory JK, Bowman FD, Anawalt BD, Matsumoto AM, et al. (2005) Exogenous testosterone $(T)$ alone or with finasteride increases physical performance, grip strength, and lean body mass in older men with low serum $\mathrm{T}$. $\mathrm{J}$ Clin Endocrinol Metab 90: 1502-1510.

7. Hale SL, Birnbaum Y, Kloner RA (1997) Estradiol, Administered Acutely, Protects Ischemic Myocardium in Both Female and Male Rabbits. J Cardiovasc Pharmacol Ther 2: 47-52.

8. Hale SL, Birnbaum Y, Kloner RA (1996) beta-Estradiol, but not alpha-estradiol, reduced myocardial necrosis in rabbits after ischemia and reperfusion. Am Heart J 132: 258-262.

9. Booth EA, Lucchesi BR (2008) Estrogen-mediated protection in myocardial ischemia-reperfusion injury. Cardiovasc Toxicol 8: 101-113.

10. Das B, Sarkar C (2006) Similarities between Ischemic Preconditioning and 17[beta]-Estradiol Mediated Cardiomyocyte KATP Channel Activation Leading to Cardioprotective and Antiarrhythmic Effects during Ischemia/Reperfusion in the Intact Rabbit Heart. J Cardiovasc Pharmacol 47: 277-286.

11. Herring MJ, Oskui PM, Hale SL, Kloner RA (2013) Testosterone and the cardiovascular system: a comprehensive review of the basic science literature. J Am Heart Assoc 2: e000271.

12. Pham TV, Sosunov EA, Anyukhovsky EP, Danilo P Jr, Rosen MR (2002) Testosterone diminishes the proarrhythmic effects of dofetilide in normal female rabbits. Circulation 106: 2132-2136.

13. Brouillette J, Rivard K, Lizotte E, Fiset C (2005) Sex and strain differences in adult mouse cardiac repolarization: importance of androgens. Cardiovasc Res 65: 148-157.

14. Bai CX, Kurokawa J, Tamagawa M, Nakaya H, Furukawa T (2005) Nontranscriptional regulation of cardiac repolarization currents by testosterone. Circulation 112: 1701-1710.

15. Khaw KT, Dowsett M, Folkerd E, Bingham S, Wareham N, et al. (2007) Endogenous testosterone and mortality due to all causes, cardiovascular disease, and cancer in men: European prospective investigation into cance in Norfolk (EPIC-Norfolk) Prospective Population Study. Circulation 116: $2694-$ 2701.

16. Malkin CJ, Pugh PJ, West JN, van Beek EJ, Jones TH, et al. (2006) Testosterone therapy in men with moderate severity heart failure: a double-blind randomized placebo controlled trial. Eur Heart J 27: 57-64.

17. Estrada M, Varshney A, Ehrlich BE (2006) Elevated testosterone induces apoptosis in neuronal cells. J Biol Chem 281: 25492-25501.
18. Jia Y, Hikim AP, Lue YH, Swerdloff RS, Vera Y, et al. (2007) Signaling pathways for germ cell death in adult cynomolgus monkeys (Macacafascicularis) induced by mild testicular hyperthermia and exogenous testosterone treatment. Bio Reprod 77: 83-92.

19. Wang M, Tsai BM, Kher A, Baker LB, Wairiuko GM, et al. (2005) Role of endogenous testosterone in myocardial proinflammatory and proapoptotic signaling after acute ischemia-reperfusion. Am J Physiol Heart CircPhysio 288: $\mathrm{H} 221-226$.

20. Huang C, Gu H, Zhang W, Herrmann JL, Wang M (2010) Testosterone-downregulated Akt pathway during cardiac ischemia/reperfusion: a mechanism involving BAD, Bcl-2 and FOXO3a. J Surg Res 164: e1-11.

21. Basaria S, Coviello AD, Travison TG, Storer TW, Farwell WR, et al. (2010) Adverse Events Associated with Testosterone Administration - NEJM. N Engl J Med 363:109-122.

22. Bhasin S, Storer TW, Berman N, Callegari C, Clevenger B, et al. (1996) The effects of supraphysiologic doses of testosterone on muscle size and strength in normal men. $\mathrm{N}$ Engl J Med 335: 1-7.

23. WS R. ImageJ. Bethesda, MD Natl. Institutes Heal.

24. Vincent GM, Timothy KW, Leppert M, Keating M (1992) The spectrum of symptoms and QT intervals in carriers of the gene for the long-QT syndrome. N Engl J Med 327: 846-852.

25. vanNoord C, Dörr M, Sturkenboom MC, Straus SM, Reffelmann T, et al. (2010) The association of serum testosterone levels and ventricular repolarization. Eur J Epidemiol 25: 21-28.

26. PecoriGiraldi F, Toja PM, Filippini B, Michailidis J, Scacchi M, et al. (2010) Increased prevalence of prolonged QT interval in males with primary or secondary hypogonadism: a pilot study. Int J Androl 33: e132-138.

27. Drew BJ, Califf RM, Funk M, Kaufman ES, Krucoff MW, et al. (2004) Practice standards for electrocardiographic monitoring in hospital settings: an American Heart Association scientific statement from the Councils on Cardiovascular Nursing, Clinical Cardiology, and Cardiovascular Disease in the Young: endorsed by the International Society of Computerized Electrocardiology and the American Association of Critical-Care Nurses. Circulation 110: 2721-2746.

28. Schroeder CA, Smith LJ (2011) Respiratory rates and arterial blood-gas tensions in healthy rabbits given buprenorphine, butorphanol, midazolam, or their combinations. J Am Assoc Lab Anim Sci 50: 205-211.

29. Liu J, Tsang S, Wong TM (2006) Testosterone is required for delayed cardioprotection and enhanced heat shock protein 70 expression induced by preconditioning. Endocrinology 147: 4569-4577.

30. Tsang S, Wu S, Liu J, Wong TM (2008) Testosterone protects rat hearts against ischaemic insults by enhancing the effects of alpha(1)-adrenoceptor stimulation. Br J Pharmacol 153: 693-709.

31. Vigen R, O'Donnell Cl, Barón AE, Grunwald GK, Maddox TM, et al. (2013) Association of testosterone therapy with mortality, myocardial infarction, and stroke in men with low testosterone levels. JAMA 310: 1829-1836.

32. Antzelevitch C, Pollevick GD, Cordeiro JM, Casis O, Sanguinetti MC, et al (2007) Loss-of-function mutations in the cardiac calcium channel underlie a new clinical entity characterized by ST-segment elevation, short QT intervals, and sudden cardiac death. Circulation 115: 442-449.

33. Brugada R, Hong K, Dumaine R, Cordeiro J, Gaita F, et al. (2004) Sudden death associated with short-QT syndrome linked to mutations in HERG. Circulation 109: 30-35.

34. Tsilidis KK, Rohrmann S, McGlynn KA, Nyante SJ, Lopez DS, et al. (2013) Association between endogenous sex steroid hormones and inflammatory biomarkers in US men. Andrology 1: 919-928. 